\title{
Infrequent Occurrence of Peach Skin Streaking and the Role of Rainwater Attributes on Symptom Development
}

\author{
L. T. Schmitz and G. Schnabel ${ }^{\dagger}$ \\ Department of Plant and Environmental Sciences, Clemson University, Clemson, SC 29634
}

\begin{abstract}
Streaks lacking pigmentation have impacted red blush cultivars of peaches in many East Coast production areas, but the underlying cause is still unclear. Some evidence suggests that streaking may be caused by reactive agents in rainwater. Peach skin streaking was monitored over two consecutive years at a commercial farm with a history of streaking problems located near Ridge Spring, SC. Six cultivars (two early season, two midseason, and two late season) were evaluated, each in two locations (LocA and LocB). Among those 12 experimental block cultivars, streaking occurred only in 2017 in cv. Scarletprince of LocA with an incidence of $6 \%$. That same year two nearby nonexperimental blocks with 'Scarletprince' revealed 11 and 25\% streaking. Streaking was also monitored at the Musser Fruit Research Center (MFRC) in Seneca, SC. At that location, a high incidence of streaking was observed, with 50 and 64\% in 'Julyprince' (2017) and 'Carored' (2018), respectively. Rainwater $\mathrm{pH}$ taken from each of the 12 experimental blocks ranged from 3.03 to 7.4 , ozone $\left(\mathrm{O}_{3}\right)$ levels ranged from $<0.02$ to $0.37 \mathrm{mg} /$ liter, and chlorine

Although the electrical conductivity (EC) was below $100 \mu \mathrm{S} / \mathrm{cm}$ on average, we did measure EC values as high as $1,500 \mu \mathrm{S} / \mathrm{cm}$. For all samples, the oxidation-reduction potential (ORP) ranged from 90 to $302 \mathrm{mV}$, indicating oxidizing conditions. Fruit harvested 1 or 2 weeks prior to commercial maturity and treated with solutions of high (10) or low (3) $\mathrm{pH}$, ozone $>0.37 \mathrm{mg} / \mathrm{liter}$, and $\mathrm{EC}$ values of up to $3,000 \mu \mathrm{S} / \mathrm{cm}$ did not produce symptoms. However, streaking was reproduced with collected rainwater, but the remaining sample volume did not allow further analyses. Using $0.05 \% \mathrm{ClO}_{2}$ to induce streaking, we show that fruit of different cultivars varied in susceptibility when treated 1 week prior to commercial maturity, with 'Juneflame' being the most susceptible and 'August Lady' being the least susceptible. Our study shows that multiple factors determine the occurrence of streaking in peach orchards, including cultivar susceptibility, ripening stage, and the presence of rainwater with sufficient amounts of a yet unknown reactive agent or agent combination.
\end{abstract} $\left(\mathrm{Cl}_{2}\right)$ and chlorine dioxide $\left(\mathrm{ClO}_{2}\right)$ levels were either just above or under the detection limit of $0.01 \mathrm{mg} / \mathrm{liter}$ and $0.02 \mathrm{mg} /$ liter, respectively.
Keywords: abiotic, tree fruits, epidemiology, climate/weather effects
Peach fruit appearance, aka "finish," greatly influences consumer acceptance and marketability. Final fruit quality is affected by all decisions and practices throughout production from site and cultivar selection to postharvest handling (Crisosto et al. 1995). Because of consumer preference, the peach industry prefers to grow large, red fruit. To make fruit suitable for postharvest handling and to avoid blemishes during transportation, the fruit must be firm when picked (Layne 2007). Fruit of poor quality, including smaller and misshapen fruit, is likely to get a reduced price or may even get rejected by the retailer. Peach skin discolorations, such as inking (Crisosto et al. 1999), skin burning (Cantín et al. 2011), and suture red spot (MacLean et al. 1984) impair fruit finish and lower marketability.

Peach skin streaking is another form of skin discoloration and was only recently described in the scientific literature (Hu et al. 2017). It was first observed in 2003 at a fruit research station near Byron, GA (P. Brannen, UGA, personal communication). Since then streaking has become more prevalent and in some years has become a major issue for South Carolina growers. Substantial damage in multiple cultivars was reported in 2015 and 2016, and depending on location and cultivar, streaking severity varied from barely visible to necrotic

${ }^{\dagger}$ Corresponding author: G. Schnabel; schnabe@clemson.edu

Technical contribution no. 6734 of the Clemson University Experiment Station.

Funding: This material is based upon work supported by the South Carolina Peach Council, Southern Region SARE OS17-109, and NIFA/USDA project number SC-1700501.

The author(s) declare no conflict of interest.

Accepted for publication 22 April 2019.

() 2019 The American Phytopathological Society streaks (unpublished data). Peach fruit with streaking was also reported in Pennsylvania and Maryland peach orchards as recently as 2018 (M. Shannon, personal communication).

Streaking affects red-blush cultivars in both conventional and organic production, essentially eliminating synthetic pesticides as possible contributors (Hu et al. 2017). Streaks can be faint yellow, solid yellow, or even necrotic brown in color, extending in general from the stem of the fruit to the tip end following the flow of liquid over the fruit surface. Fruit with solid yellow or necrotic brown stripes are unmarketable. Symptoms on fruit have not been associated with foliar damage, and underlying causes of peach skin streaking are still unknown. Based on field observations, the occurrence of preharvest streaking was associated with light rain 1 to 2 weeks prior to harvest preceding a period of drought of about 10 days (Hu et al. 2017). Rainwater may therefore concentrate atmospheric pollutants at high enough doses to damage peach skin.

Multiple attributes of rainwater have been shown to cause harm to plant tissue. The $\mathrm{pH}$ of rainwater may cause epidermal defects, reductions in crop yield (Proctor 1983; Rinallo and Modi 1995), and discoloration of peach skin in association with ionic contaminants (Cheng and Crisosto 1994). The stability of anthocyanins, which are increasingly synthesized during peach fruit maturation, is also highly dependent on $\mathrm{pH}$ (Torskangerpoll and Andersen 2005). Chlorine in irrigation water has also been reported to induce stunting and foliar damage on several nursery crops (Cayanan et al. 2008). Ozone $\left(\mathrm{O}_{3}\right)$ causes leaf injury and impaired growth of several crops, including tomato and rice (Sawada and Kohno 2009; Wohlgemuth et al. 2002). Finally, there is a possibility that leaf exudates concentrated in rainwater may be responsible for streaking symptoms.

The objectives of this study were to (i) monitor the occurrence of peach skin streaking over two consecutive seasons in multiple cultivars at a commercial farm in South Carolina; (ii) determine the distribution of streaking within a canopy; (iii) monitor chemical attributes in rainwater suspected to be streaking agents over the course of the peach fruit ripening season and assess their ability to 
produce streaking on peach fruit; and (iv) assess the influence of ripening stage on the susceptibility of peach fruit to streaking.

\section{Materials and Methods}

Experimental locations. Six peach cultivars, including 'Blazeprince' (ripening late June), 'Scarletprince' (ripening early July), 'Redskin' (ripening mid-July), 'O'Henry' (ripening late July), 'August Lady' (ripening early August), and 'September Sun' (ripening mid-August), were monitored for streaking in two different locations (LocA and LocB) at a commercial farm in South Carolina. LocA was near Trenton $\left(33^{\circ} 45^{\prime} 36.4^{\prime \prime} \mathrm{N}, 81^{\circ} 49^{\prime} 08.0^{\prime \prime} \mathrm{W}\right)$, and LocB was near

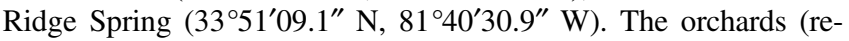
ferred to as experimental blocks) in LocA and LocB were clustered within a 10 - and 16-km-diameter circle (referred to as cluster), respectively, and the two clusters were separated by at least $6 \mathrm{~km}$. According to the farm operator, some experimental block cultivars near Trenton (LocA) exhibited streaking symptoms in previous years that rendered many fruit unmarketable. Both experimental blocks received the same pesticide treatments in both years for pest and disease management starting with oil sprays at dormancy and ending with preharvest applications for brown rot management. In addition, peach cultivars at the Musser Fruit Research Center (MFRC) in Seneca, SC (34 $\left.36^{\prime} 11^{\prime \prime} \mathrm{N}, 82^{\circ} 52^{\prime} 43^{\prime \prime} \mathrm{W}\right)$ were monitored for streaking occurrence. This research station is located $160 \mathrm{~km}$ northwest of the commercial farm. All locations were monitored throughout the growing seasons of 2017 and 2018. The trees used for this study were all 6 to 8 years old and in full production.

Assessment of streaking occurrence. Fruit were examined weekly for streaking symptoms starting 4 weeks prior to harvest. For each experimental block cultivar, streaking incidence was determined on 50 arbitrarily selected fruit per tree for 5 single trees with at least 2 buffer trees between each experimental tree. To assess distribution of streaking within the tree canopy, incidence was recorded for fruit at the top, bottom, inside, and sides of the canopy. For each position, 25 fruit were arbitrarily selected and evaluated.

Rainwater analysis. Rainwater was collected from each experimental block, and attributes, including $\mathrm{pH}$, electrical conductivity (EC), oxidation-reduction potential (ORP), chlorine species $\left(\mathrm{Cl}_{2}\right.$, $\left.\mathrm{ClO}_{2}\right)$, and ozone $\left(\mathrm{O}_{3}\right)$, were assessed for their ability to cause streaking symptoms. AcuRite rain gauges $(12.5 \mathrm{~cm}$; Chaney Instrument Co., Lake Geneva, WI) as well as polyethylene bins (7.5 L, $24 \mathrm{~cm}$; Lowe's Companies, Inc., Mooresville, NC) were set up in each experimental block to measure precipitation and collect rainwater for analysis. Collection bins were examined for rain twice a week or when forecasts predicted a $30 \%$ or greater chance of rain starting 4 weeks prior to harvest. The frequent collection schedule was implemented to minimize potential impacts of temperature and light on the rainwater chemistry. At each inspection, the bins were cleaned with DI water. Rainwater was transferred into 500-ml polyethylene bottles (SKS Bottle and Packaging, Inc., Watervliet, NY) and placed on ice for transportation. Samples were analyzed at room temperature within $24 \mathrm{~h}$ of sampling. Oxidation reduction potential (ORP), electrical conductivity (EC), and $\mathrm{pH}$ were determined in a $100-\mathrm{ml}$ aliquot. ORP was measured using the RE300 ExStik ORP meter (Extech Instruments, Nashua, $\mathrm{NH}$ ). EC and $\mathrm{pH}$ were measured using the $\mathrm{pH} /$ conductivity tester PHH-7200 (Omega Engineering, Surrey, UK). Rain samples and leaf rinsate exhibiting low ionic strength (less than $100 \mu \mathrm{S} / \mathrm{cm}$ ) were treated with pHisa ionic strength adjustor (Thermo Scientific, Waltham, MA) for improved accuracy and stability. The EC electrode was calibrated according to manual instructions, and $\mathrm{pH}$ electrode was calibrated using Orion pure water $\mathrm{pH}$ buffers (Thermo Scientific, Waltham, MA). Instruments were calibrated weekly. Chlorine species $\left(\mathrm{Cl}_{2}, \mathrm{ClO}_{2}\right)$ and ozone $\left(\mathrm{O}_{3}\right)$ in rainwater were quantified with the AQUAfast AQ3700 colorimetry meter (Thermo Scientific, Waltham, MA) and respective test reagents $\mathrm{AC} 2070$ for $\mathrm{Cl}_{2}, \mathrm{AC} 2099$ for $\mathrm{ClO}_{2}$, and $\mathrm{AC} 3048$ for $\mathrm{O}_{3}$ (Thermo Scientific Orion, Waltham, MA).

Preparation of leaf rinsate. Leaf samples were collected from experimental block cultivars after at least 10 days of no rain to investigate the potential for leaf rinsate to cause streaking symptoms. Ten leaves closest to the fruit were collected from five trees, totaling 50 leaves per block. Leaf samples from the 6 experimental block cultivars within LocA were pooled, and so were leaf samples within LocB to yield 300 leaves for each of the two locations. Each leaf collection was rinsed by adding 50 leaves at a time to $250 \mathrm{ml}$ of distilled water in a 500-ml flask with screw cap. Then the flask was inverted several times for $30 \mathrm{~s}$. Rinsed leaves were removed from the rinsate, and a fresh set of 50 leaves was added to the same liquid until 300 leaves were processed. The LocA and LocB rinsate was examined separately for the ability to cause streaking symptoms on detached, immature fruit.

Generation of streaking symptoms on immature fruit. Fruit were harvested 1 and 2 weeks prior to commercial maturity for detached fruit experiments in the laboratory. The ripening status was estimated based on visual assessments during fruit maturation. Fruit used for experiments were collected from the commercial farm and included fruit from 'August Lady', 'Blazeprince', 'Fireprince', 'Gloria', 'Julyprince', 'Juneflame', 'O'Henry', 'Redglobe', 'Redskin', 'Scarletprince', and 'September Sun'. Sodium chloride ( $\mathrm{NaCl}$; Fisher Scientific, Hampton, NH) was evaluated at concentrations of $700 \mu \mathrm{g} / \mathrm{ml}$ and $1,500 \mu \mathrm{g} / \mathrm{ml}$. These were chosen based on EC value extremes detected in rainwater samples. Chlorine dioxide solutions were generated according to $\mathrm{Hu}$ et al. (2017) using the Aquamira Chlorine Dioxide Water Treatment kit (Aquamira Technologies, Inc., Logan, UT). Equal amounts of solutions part A and part B were mixed for 5 min to generate $1 \%$ active $\mathrm{ClO}_{2}$, which was further diluted to $0.05 \%(500 \mu \mathrm{g} / \mathrm{ml})$. The concentration of $\mathrm{ClO}_{2}$ was chosen based on $\mathrm{Hu}$ et al. (2017), who reported $\mathrm{ClO}_{2}$ at concentrations of $0.02 \%$ induced streaking symptoms on immature peach fruit. Water solutions were adjusted to $\mathrm{pH} 3$ and $\mathrm{pH} 10$ using sulfuric acid $\left(\mathrm{H}_{2} \mathrm{SO}_{4}\right.$; VWR, Radnor, PA) and sodium hydroxide ( $\mathrm{NaOH}$; Fisher Scientific, Hampton, NH), respectively. To examine possible combination effects, mixtures of $700 \mu \mathrm{g} / \mathrm{ml} \mathrm{NaCl}+\mathrm{pH} 3$ solution, $700 \mu \mathrm{g} / \mathrm{ml} \mathrm{NaCl}+$ pH 10 solution, $500 \mu \mathrm{g} / \mathrm{ml} \mathrm{ClO}_{2}+\mathrm{pH} 10$ solution, $1,500 \mu \mathrm{g} / \mathrm{ml} \mathrm{NaCl}+$ $500 \mu \mathrm{g} / \mathrm{ml} \mathrm{ClO}_{2}$, and $1,500 \mu \mathrm{g} / \mathrm{ml} \mathrm{NaCl}+500 \mu \mathrm{g} / \mathrm{ml} \mathrm{ClO}_{2}+\mathrm{pH} 10$ were also applied. Additional treatments consisted of leaf rinsate. Treatments were applied to three equally distant spots on the fruit starting from the shoulder of the stem end using a 1,000 $\mu$ l pipette (Eppendorf, Hamburg, Germany). A total of $300 \mu \mathrm{l}$ of treatment solution was pipetted onto the fruit surface as droplets in a single drip line. To ensure slow droplet run-off, a nonionic surfactant (INDUCE; BASF, Ludwigshafen, Germany) was added at $0.125 \%$ to all solutions, including the water control. The addition of a surfactant to the individual treatments increased retention and made the drops stick to the fruit simulating slow run-off in the field. The surfactant did not cause symptoms by itself. Three single-fruit replicates were used per treatment, and each experiment was repeated at least once. All treatment solutions were prepared immediately prior to application. Pictures of experimental fruit were taken every $24 \mathrm{~h}$ after treatment for 7 days.

The ability of ozone $\left(\mathrm{O}_{3}\right)$ to generate streaking was evaluated in a separate study. The trials were conducted in the early morning hours from 5 A.M. to 6 A.M. to ensure slow drying conditions. Immature fruit, 1 and 2 weeks shy of commercial maturity, of 'Cresthaven' were subjected to ozone treatments at a concentration of $0.3 \mu \mathrm{g} / \mathrm{ml}$. A leaf was mounted on each experimental fruit vertically and tip pointing to the fruit using a metal mesh wire contraption. That allowed treatment solutions to persistently run over the fruit surface. The mounted leaves were misted with a hand-held sprayer to run-off and rewetted every 10 to $15 \mathrm{~min}$ for $60 \mathrm{~min}$ to ensure a constant supply of spray solution drip. Ozone treatments were generated in $250 \mathrm{ml}$ distilled water using the Aqua-6 Ozone Generator (A2Z Ozone Inc., Louisville, KY). Ozonation was conducted for 2 min within $10 \mathrm{~min}$ of the first application. Each treatment was conducted on five trees with three singlefruit replicates per fruit for each maturity stage. The experiment was repeated.

Statistical analysis. Using JMP Pro version 14.1.0 (SAS Institute Inc., Cary, NC), we tested for relationships between precipitation and rainwater attributes. Simple linear regressions were evaluated between (i) precipitation and $\mathrm{pH}$, (ii) precipitation and 
electrical conductivity, (iii) precipitation and oxidation/reduction potential, (iv) precipitation and chlorine, (v) precipitation and chlorine dioxide, and (vi) precipitation and ozone at $P<0.05$. To confirm significant relationships, correlation analysis was estimated by Row-wise method for precipitation and $\mathrm{O}_{3}$, and REML method for precipitation and ORP. ANOVA analysis was used to determine a relationship between reproduction of streaking and ripening status of peach fruit. Where relationships were significant $(P<0.05)$, we compared means between cultivars using Fisher's LSD student's $t$ test.

\section{Results}

Streaking occurrence and incidence in 2017 and 2018 growing season. Streaking was only observed in the experimental block 'Scarletprince' of LocA in 2017 with 6\% incidence. None of the other experimental block cultivars in LocB exhibited streaking. However, streaking with incidences of 11 and 25\% was observed in two nonexperimental blocks with 'Scarletprince' situated within LocA that same year. Streaking was not observed in either block in 2018; however, a nonexperimental block with 'Harvester' located within LocB exhibited 23\% streaking. At the MFRC in Clemson, SC mild streaking occurred on multiple cultivars, including 'Scarletprince', 'August Prince', and 'O'Henry' (J. C. Melgar, Clemson, personal communication), but the highest incidence was observed in midseason 'Julyprince' in 2017 (50\% incidence) and in earlyseason 'Carored' in 2018 (64\% incidence).

Distribution of streaking within single tree canopies. Distribution of streaking within single tree canopies differed between locations. In the commercial orchards, fruit from the top and canopy

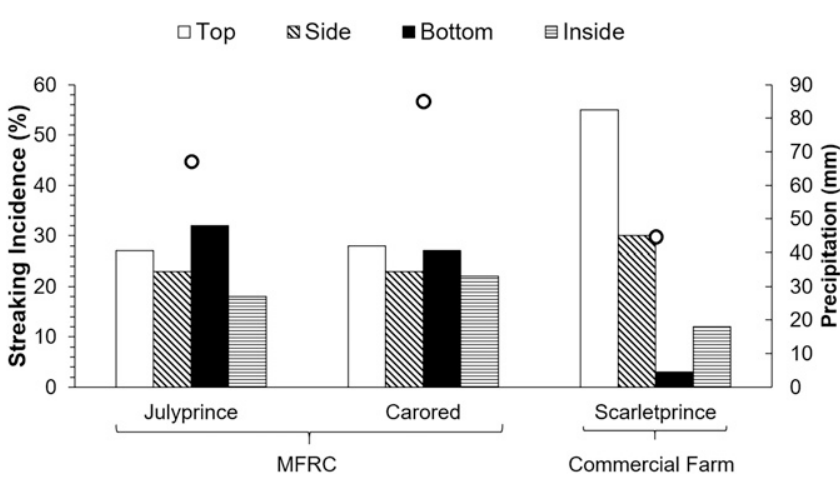

Fig. 1. Distribution of streaking within single tree canopies (bars) and cumulated precipitation (open circle) 7 days prior to symptom development in cvs. Julyprince and Carored at Musser Fruit Research Center (MFRC) and cv. Scarletprince at a commercial farm near Ridge Spring, South Carolina. sides were predominantly affected, while symptomatic fruit were distributed uniformly within the canopy at the MFRC (Fig. 1). 'Scarletprince' and 'Harvester', which were in nonexperimental blocks near LocA and LocB, revealed streaking distribution patterns within single tree canopies similar to 'Scarletprince' (data not shown). Locations with uniform streaking distribution within single tree canopies received more precipitation during the week prior to symptom development compared with the locations where fruit at the top and canopy sides were predominantly affected (Fig. 1).

Analysis of rainwater from peach orchards. A total of 205 rainwater samples were taken from 12 experimental blocks in 2017, and 2018 between mid-May and mid-August and examined for $\mathrm{pH}, \mathrm{Cl}_{2}$, and $\mathrm{ClO}_{2}$ content. Average seasonal $\mathrm{pH}$ values ranged from 5.18 to 6.38 between locations in 2017 and from 4.90 to 6.55 in 2018 (Table 1). In both years, the median $\mathrm{pH}$ of all samples compiled was greater than 5.85 . The minimum $\mathrm{pH}$ value recorded was 4.1 in 2017 and 3.03 in 2018, while the maximum $\mathrm{pH}$ value was 7.4 in 2017 and 7.01 in 2018 (Table 1). In both years, levels of chlorine $\left(\mathrm{Cl}_{2}\right)$ and chlorine dioxide $\left(\mathrm{ClO}_{2}\right)$ were either below or just above the detection limit of $0.01 \mathrm{mg} /$ liter and $0.02 \mathrm{mg} /$ liter, respectively (Table 1). Additionally, EC, ORP, and $\mathrm{O}_{3}$ were determined for samples collected in 2018. Average seasonal EC values ranged from 0 to $60 \mu \mathrm{S} / \mathrm{cm}$ between locations. However, we observed individual EC values as high as $1,505 \mu \mathrm{S} / \mathrm{cm}$ (Table 2). The ORP of all rainwater samples was positive, indicating oxidizing conditions, but did not exceed $300 \mathrm{mV}$ (Table 2). Simple linear regression revealed a significant effect of precipitation on ORP $(P<0.05)$. Further statistical analysis showed that precipitation and ORP were negatively correlated with a correlation coefficient of -0.212 based on REML method.

Similar to chlorine species, $\mathrm{O}_{3}$ levels were either below or just above the detection limit of $0.02 \mathrm{mg} / \mathrm{liter}$ on average per location (Table 2$)$, but there was a significant $(P<0.05)$ relationship between precipitation and $\mathrm{O}_{3}$. A positive correlation was estimated to be 0.3643 by Row-wise method. There were no significant relationships between precipitation and $\mathrm{pH}, \mathrm{EC}, \mathrm{Cl}_{2}$, or $\mathrm{ClO}_{2}$, respectively $(P<0.05)$. Analysis of leaf rinsate after periods of drought revealed an average $\mathrm{pH}$ of 5.01 and 5.22, average EC of 13 and $23 \mu \mathrm{S} / \mathrm{cm}$, and average ORP of 173 and $163 \mathrm{mV}$ for locations A and $\mathrm{B}$, respectively (data not shown). For both locations (A and B), average values of $\mathrm{Cl}_{2}, \mathrm{ClO}_{2}$, and $\mathrm{O}_{3}$ were under the respective detection limits $0.01,0.02$, and $0.02 \mu \mathrm{g} / \mathrm{ml}$, respectively (data not shown).

Development of streaking symptoms and relationship to ripening status of peach fruit. Rainwater attributes including $\mathrm{pH}$ and $\mathrm{EC}$ extremes as well as leaf rinsate did not cause symptoms on detached fruit picked 1 and 2 weeks prior to harvest (Table 3 ). Likewise, neither $\mathrm{NaCl}$ at concentrations of $700 \mu \mathrm{g} / \mathrm{ml}$, solutions of $\mathrm{pH} 3$ or 10 ,

Table 1. Precipitation, $\mathrm{pH}$, chlorine $\left(\mathrm{Cl}_{2}\right)$, and chlorine dioxide $\left(\mathrm{ClO}_{2}\right)$ in rainwater collected over 2 years from 12 experimental blocks of a commercial farm in South Carolina

\begin{tabular}{|c|c|c|c|c|c|c|c|}
\hline $\begin{array}{l}\text { Location within } \\
\text { commercial farm }\end{array}$ & Cultivar & $\begin{array}{c}\text { Weekly } \\
\text { precipitation }(\mathbf{m m})\end{array}$ & $\begin{array}{c}\text { Total } \\
\text { precipitation }(\mathbf{m m})\end{array}$ & pH & pH range ${ }^{a}$ & $\mathrm{Cl}_{2}(\boldsymbol{\mu g} / \mathrm{ml})$ & $\mathrm{ClO}_{2}(\mu \mathrm{g} / \mathrm{ml})$ \\
\hline \multirow[t]{6}{*}{ Location A } & Blazeprince & $29.97 / 25.91^{b}$ & $298 / 311$ & $6.07 / 5.55$ & $4.7-6.9 / 3.0-6.5$ & $0.02 /<0.03$ & $<0.02 /<0.03$ \\
\hline & Scarletprince & $14.48 / 32.77$ & $145 / 394$ & $6.34 / 5.81$ & $5.1-7.4 / 3.7-7.0$ & $0.03 /<0.01$ & $<0.02 /<0.02$ \\
\hline & Redskin & 42.67 / 29.21 & $425 / 349$ & $5.89 / 4.90$ & $4.7-6.6 / 3.9-5.9$ & $0.02 /<0.01$ & $<0.02 /<0.02$ \\
\hline & O’Henry & $14.99 / 23.88$ & $149 / 286$ & $6.38 / 5.79$ & $5.9-6.9 / 4.0-6.7$ & $0.02 / 0.02$ & $<0.02 / 0.02$ \\
\hline & August Lady & $21.08 / 37.59$ & $210 / 451$ & $6.1 / 5.61$ & $5.6-6.3 / 3.9-6.3$ & $0.02 / 0.01$ & $<0.02 / 0.02$ \\
\hline & September Sun & $31.75 / 24.38$ & $318 / 368$ & $6.19 / 6.48$ & $5.3-7.0 / 6.0-7.0$ & $0.03 / 0.01$ & $0.02 / 0.04$ \\
\hline \multirow[t]{6}{*}{ Location B } & Blazeprince & $19.56 / 35.56$ & $196 / 425$ & $5.85 / 5.89$ & $4.5-6.5 / 5.5-6.4$ & $0.01 / 0.01$ & $<0.02 / 0.09$ \\
\hline & Scarletprince & $17.53 / 14.22$ & $174 / 127$ & $6.34 / 6.31$ & $5.5-6.9 / 5.8-7.0$ & $0.02 / 0.02$ & $<0.02 / 0.02$ \\
\hline & Redskin & $27.43 / 20.57$ & $273 / 248$ & $5.76 / 5.37$ & $4.6-6.6 / 4.7-5.9$ & $0.02 / 0.02$ & $<0.02 /<0.02$ \\
\hline & O’Henry & $25.15 / 34.04$ & $250 / 375$ & $5.3 / 5.72$ & $4.2-6.2 / 5.1-6.2$ & $0.02 / 0.01$ & $<0.02 /<0.02$ \\
\hline & August Lady & $21.84 / 24.89$ & $218 / 298$ & $6.4 / 6.55$ & $5.1-7.3 / 6.0-6.7$ & $0.02 / 0.01$ & $<0.02 / 0.03$ \\
\hline & September Sun & $24.13 / 20.32$ & $241 / 222$ & $5.18 / 5.42$ & $4.1-6.1 / 4.2-6.4$ & $0.01 / 0.01$ & $0.07 / 0.03$ \\
\hline
\end{tabular}

\footnotetext{
a Minimum and maximum value recorded for cultivar in respective location and experimental year.
}

${ }^{b}$ Numbers separated by ' $\%$ ' indicate values from experimental years 2017 (left) and 2018 (right). 
or mixtures of $700 \mu \mathrm{g} / \mathrm{ml} \mathrm{NaCl}$ and $\mathrm{pH} 3$ or 10 produced streaking symptoms (Table 3 ). $\mathrm{ClO}_{2}$ at $500 \mu \mathrm{g} / \mathrm{ml}$ generated streaking symptoms on ripening fruit (Table 3). Susceptibility to streaking was dependent on fruit maturity and cultivar. Among fruit that was collected 7 days prior to commercial harvest, 'Juneflame', 'Blazeprince', 'Redglobe', 'September Sun', and 'Julyprince' were most susceptible. 'Juneflame' was significantly more susceptible than 'O'Henry', 'Redskin', and 'August Lady' (Figs. 2 and 3). Among fruit harvested 2 weeks before harvest, 'Gloria' was significantly more susceptible than 'September Sun' and 'Scarletprince' (Fig. 4). Ozone at $0.3 \mu \mathrm{g} / \mathrm{ml}$ did not produce symptoms on hanging, treated fruit 1 or 2 weeks prior to commercial harvest (data not shown).

\section{Discussion}

Monitoring of streaking in 6 cultivars over two consecutive growing seasons suggested that peach skin streaking is an infrequent, noncultivar-specific, and localized phenomenon. In one year, streaking appeared in one cultivar of a specific location, and in another, it showed up at a different location and cultivar on the same farm. Likewise, streaking appeared in the same year in one cultivar but not in another nearby. This impeded predictability considerably; however, this also indicated that the occurrence of streaking does not predict continuation of the problem that same year in other cultivars or in the same cultivar the next year. However, streaking did cause significant damage. We recorded incidences of up to $64 \%$. While streaked peaches may be acceptable for local markets, such fruit will experience significant downgrades at the retail level. At best they may qualify for U.S. Grade No. 2, the lowest of four USDA Peach Grades and Standards (USDA Agricultural Marketing Service 2004). Due to the nature of symptom development close to commercial harvest, streaking often goes unnoticed during the production season until harvest.

Our data suggested that the distribution of streaking in single tree canopies appeared to be influenced by the amount of rainfall associated with the streaking incidence. During heavy rainfall (i.e., more than $25 \mathrm{~mm}$ per day), it is more likely that the entire canopy will be wetted evenly, resulting in similar streaking incidence among canopy positions. For light rain events, however, it is reasonable to assume that fruit at the top and sides of the canopy are wetted predominantly, which may lead to localized incidence within single tree canopies. However, more data are needed to conclusively determine the true nature of the relationship between rainfall and streaking occurrence in single tree canopies. There are also alternative explanations that may be considered. The susceptibility to streaking

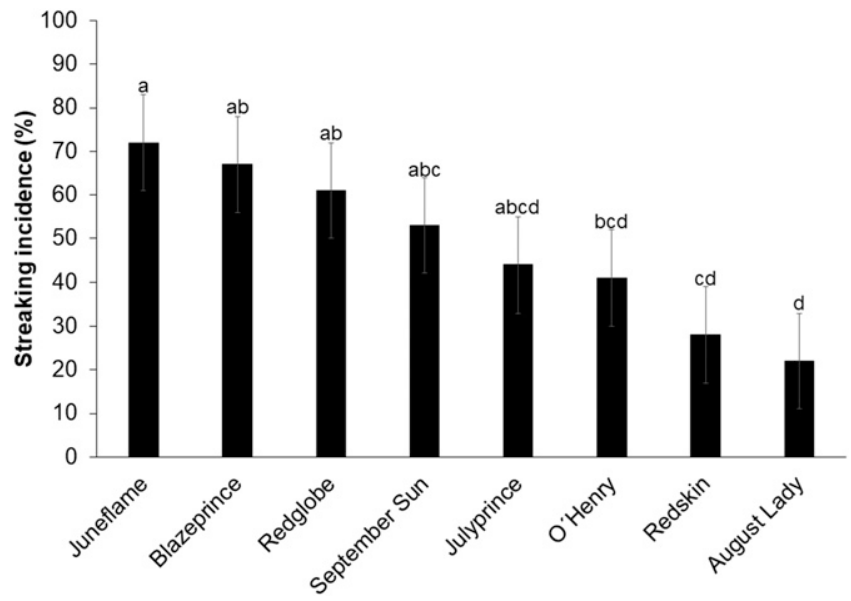

Fig. 2. Streaking incidence on fruit picked one week prior to commercial harvest and treated with $500 \mu \mathrm{g} / \mathrm{ml}$ chlorine dioxide $\left(\mathrm{ClO}_{2}\right)$ solution. LSD test (alpha $\left.=0.05\right)$, error bars represent $\pm 11 \mathrm{SE}$. Different letters represent significantly different responses between cultivars.

Table 2. Electrical conductivity (EC), oxidation-reduction potential (ORP), and ozone $\left(\mathrm{O}_{3}\right)$ content mean values of rainwater collected in 2018 from 12 experimental blocks of a commercial farm in South Carolina

\begin{tabular}{llclcccc}
\hline Commercial farm & Cultivar & EC $(\boldsymbol{\mu S} / \mathbf{c m})$ & EC range & ORP $(\mathbf{m V})$ & ORP range & $\mathbf{O}_{\mathbf{3}}(\boldsymbol{\mu g} / \mathbf{m l})$ & $\mathbf{O}_{\mathbf{3}} \mathbf{r a n g e}$ \\
\hline Location A & Blazeprince & 11 & $0-56$ & 197 & $129-252$ & $<0.02$ & $<0.02$ \\
& Scarletprince & 69 & $0-1,505$ & 206 & $149-263$ & 0.06 & $<0.02-0.37$ \\
& Redskin & 8 & $0-72$ & 242 & $151-302$ & 0.04 & $<0.02-0.30$ \\
& O'Henry & 24 & $0-214$ & 186 & $129-279$ & 0.05 & $<0.02-0.29$ \\
& August Lady & 18 & $0-173$ & 202 & $148-273$ & $<0.02$ & $<0.02$ \\
& Sept. Sun & 34 & $0-188$ & 174 & $127-225$ & 0.02 & $<0.02-0.13$ \\
Location B & Blazeprince & 4 & $0-42$ & 158 & $98-227$ & 0.05 & $<0.02-0.31$ \\
& Scarletprince & 15 & $0-71$ & 154 & $87-203$ & 0.05 & $<0.02-0.27$ \\
& Redskin & 11 & $0-66$ & 218 & $143-269$ & 0.06 & $<0.02-0.31$ \\
& O'Henry & 0 & 0 & 177 & $90-231$ & $<0.02$ & $<0.02-0.35$ \\
& August Lady & 11 & $0-62$ & 167 & $101-208$ & $<0.02$ & $<0.02$ \\
& Sept. Sun & 9 & $0-62$ & 223 & $151-255$ & $<0.02$ & $<0.02$ \\
\hline
\end{tabular}

Table 3. Streaking symptoms induced on detached peach fruit by experimental dose

\begin{tabular}{|c|c|c|c|}
\hline Rainwater attributes & Detected range & Experimental dose & $\begin{array}{l}\text { Streaking } \\
\text { symptoms }\end{array}$ \\
\hline \multirow[t]{2}{*}{$\overline{\mathrm{pH}}$} & 3.03 to 7.4 & $\mathrm{H}_{2} \mathrm{SO}_{4} ; \mathrm{pH} 3$ & No \\
\hline & & $\mathrm{NaOH} ; \mathrm{pH} 10$ & No \\
\hline \multirow[t]{2}{*}{ Electrical conductivity (EC) } & 0 to $1,505 \mu \mathrm{S} / \mathrm{cm}$ & $\mathrm{NaCl} 700 \mu \mathrm{g} / \mathrm{ml} ; 1,500 \mu \mathrm{S} / \mathrm{cm}$ & No \\
\hline & & $\mathrm{NaCl} 1,500 \mu \mathrm{g} / \mathrm{ml} ; 3,000 \mu \mathrm{S} / \mathrm{cm}$ & No \\
\hline Oxidation reduction potential (ORP) & 90 to $302 \mathrm{mV}$ & N/A ${ }^{a}$ & N/A \\
\hline Chlorine $\left(\mathrm{Cl}_{2}\right)$ & $<0.01 \mu \mathrm{g} / \mathrm{ml}$ & $\mathrm{NaClO}>100 \mu \mathrm{g} / \mathrm{ml}^{\mathrm{b}}$ & Yes \\
\hline \multirow[t]{2}{*}{ Chlorine dioxide $\left(\mathrm{ClO}_{2}\right)$} & $<0.02 \mu \mathrm{g} / \mathrm{ml}$ & $\mathrm{ClO}_{2}>100 \mu \mathrm{g} / \mathrm{m}^{\mathrm{b}}$ & Yes \\
\hline & & $\mathrm{ClO}_{2} 500 \mu \mathrm{g} / \mathrm{ml}+\mathrm{NaCl} 1,500 \mu \mathrm{g} / \mathrm{ml}$ & Yes \\
\hline Ozone $\left(\mathrm{O}_{3}\right)$ & $<0.02-0.37 \mu \mathrm{g} / \mathrm{ml}$ & $\mathrm{O}_{3}>0.3 \mu \mathrm{g} / \mathrm{ml}$ & No \\
\hline
\end{tabular}

${ }^{a}$ N/A = not applicable. There was no treatment that specifically tested the influence of ORP on streaking development.

${ }^{\mathrm{b}}$ Based on previous data published by $\mathrm{Hu}$ et al. 2017. 
increases as fruit matures and generates more anthocyanins close to harvest (Hu et al. 2017). Photosynthetic photon flux (PPF) is greater in the upper canopy compared with the lower canopy and may lead to differences in pigment formation (Bible and Singha 1993). Hence, differences in streaking incidence with regard to canopy position may also be explained by differing ripening stages of peach fruit within single tree canopies. Lastly, pruning can impose changes on microclimates of fruit tree canopies by altering relative humidity and evaporative potential (Cooley et al. 1997). Such changes could affect exposure of the peach skin to pollutants in rainwater. Therefore, differences in canopy microclimates as a result of pruning may affect distribution of streaking within single tree canopies. However, all trees used in our experiments were open center, and pruning had been conducted to the same standards and by the same pruning crew at the commercial farm and MFRC.

The quality of rainwater varied depending on location, time, and amount of precipitation; however, none of the attributes could be associated with streaking development. Although samples were collected at regular intervals, we acknowledge the potential impact of light and temperature on water chemistry between rain events and sample collection. Rainwater attributes examined in this study included $\mathrm{pH}$ value extremes $\mathrm{pH} 3$ and 10, as well as EC value extremes 1,500 and $3,000 \mu \mathrm{S} / \mathrm{cm}$. Neither of those extremes caused streaking by themselves in our detached fruit tests. Streaking symptoms were produced recently using $\mathrm{Cl}_{2}$ or $\mathrm{ClO}_{2}$ solutions with concentrations greater than $100 \mu \mathrm{g} / \mathrm{ml}$ (Hu et al. 2017). However, levels of $\mathrm{Cl}_{2}$ or $\mathrm{ClO}_{2}$ in rainwater were significantly lower than concentrations used to induce streaking symptoms on detached fruit in the laboratory. In 2017, streaking was observed on 'Scarletprince' (LocA) at the commercial farm. This experimental block received $25 \mathrm{~mm}$ precipitation in the week prior to symptom development. Rainwater analysis revealed a pH of 6 , chlorine content of $0.02 \mu \mathrm{g} / \mathrm{ml}$ while chlorine dioxide was under the detection limit of $0.02 \mu \mathrm{g} / \mathrm{ml}$. These findings were not significantly different from rainwater collected from unaffected experimental blocks. It is still possible, however, that combinations of these attribute extremes in rainwater have the ability to damage peach skin. In one instance, we were lucky to have directly associated the occurrence of streaking on 'Carored' (2018; MFRC) after a 50-mm rainfall on May 16 and to have collected sufficient rainwater for follow-up experiments. The rainwater was stored at $4^{\circ} \mathrm{C}$ for 7 days before it was used for experiments. The stored water produced streaking symptoms on detached 'Rubyprince' fruit (pictures not shown). To the best of our knowledge, this batch of rainwater was free of pesticide residues and had never touched peach tree tissue. Unfortunately, the remaining sample volume did not allow for follow-up studies. This finding combined with our inability to reproduce symptoms with concentrated leaf rinsate further strengthens our hypothesis that rainwater alone can induce streaking.

Detached peach fruit was susceptible to streaking 2 weeks and 1 week prior to harvest, and we noticed differential responses depending on cultivar. Earlier reports confirmed that fruit skin susceptibility to streaking increases as ripening progresses, with fruit 1 week away from harvest being the most susceptible ( $\mathrm{Hu}$ et al. 2017). In this study, we show that at the same maturity stage there are cultivar differences as well. This may explain anecdotal observations from peach growers who noted that streaking occurred on one

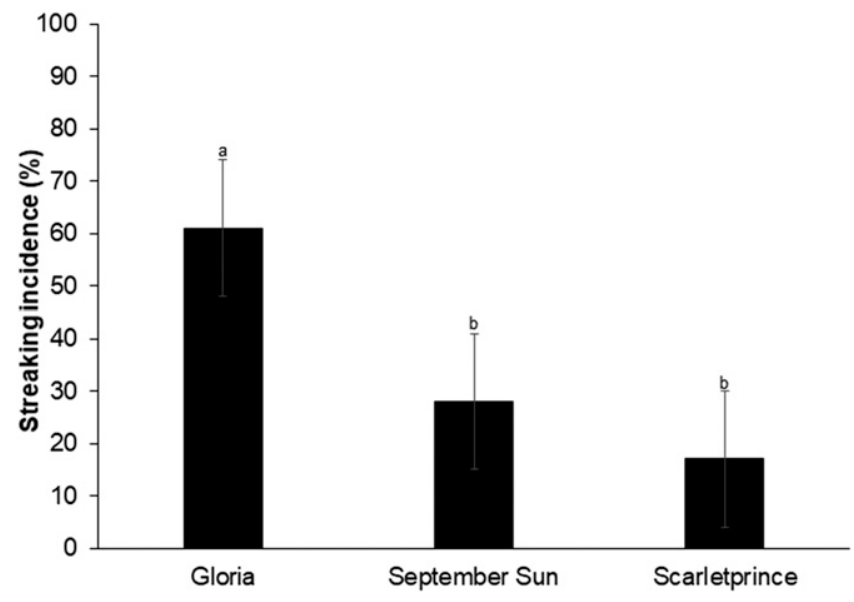

Fig. 4. Streaking incidence on fruit picked 2 weeks prior to commercial harvest and treated with $500 \mu \mathrm{g} / \mathrm{ml}$ chlorine dioxide $\left(\mathrm{ClO}_{2}\right)$ solution. LSD test (alpha $\left.=0.05\right)$, error bars represent $\pm 13 \mathrm{SE}$. Different letters represent significantly different responses between cultivars.
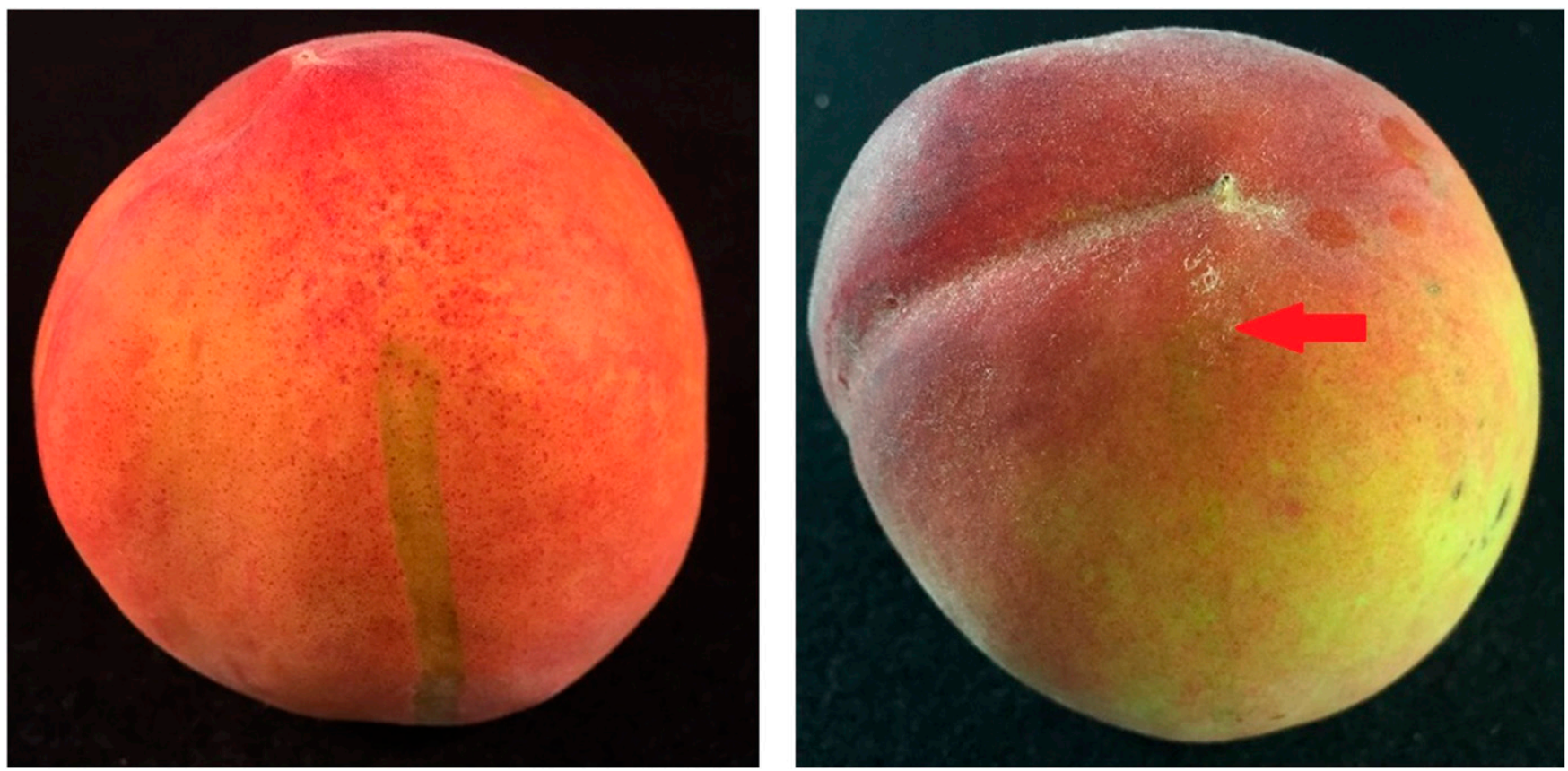

Fig. 3. Streaking on detached fruit generated using chlorine dioxide $\left(\mathrm{ClO}_{2}\right)$ at $500 \mu \mathrm{g} / \mathrm{ml} \mathrm{on} \mathrm{cv}$. Juneflame (left) and cv. August Lady (right). The point of drip treatment is indicated with an arrow, but symptoms on cv. August Lady were evident at lower frequencies. 
cultivar but adjacent cultivars of a similar ripening stage may be affected to a lesser extent or not be affected at all (M. Shannon, personal communication).

In conclusion, streaking may develop only when multiple factors coincide, including the presence of a susceptible cultivar, susceptible fruit of the susceptible cultivar at the time of rainfall, and rainwater containing one or more streaking-causing agents. The concentration of the streaking agent in rainwater is likely dependent on the amount of rainfall. Our monitoring efforts revealed very different precipitation totals in locations that were less than $2 \mathrm{~km}$ apart. For example, one field received $38 \mathrm{~mm}$ of rainfall, while another nearby field received $76 \mathrm{~mm}$ that same day (data not shown). Such differences in precipitation would greatly influence the concentration of the streaking agent in rainwater, assuming that little precipitation concentrates atmospheric pollutants more than larger precipitation.

\section{Literature Cited}

Bible, B. B., and Singha, S. 1993. Canopy position influences CIELAB coordinates of peach color. Hortic. Sci. (Prague) 28:992-993.

Cantín, C. M., Tian, L., Qin, X., and Crisosto, C. H. 2011. Copigmentation triggers the development of skin burning disorder on peach and nectarine fruit. [Prunus persica (L.) Batsch] J. Agric. Food Chem. 59:2393-2402.

Cayanan, D. F., Zheng, Y., Zhang, P., Graham, T., Dixon, M., Chong, C., and Llewellyn, J. 2008. Sensitivity of five container-grown nursery species to chlorine in overhead irrigation water. Hortic. Sci. (Prague) 43:1882-1887.

Cheng, G. W., and Crisosto, C. H. 1994. Development of dark skin discoloration on peach and nectarine fruit in response to exogenous contaminations. J. Am. Soc. Hortic. Sci. 119:529-533.
Cooley, D. R., Gamble, J. W., and Autio, W. R. 1997. Summer pruning as a method for reducing flyspeck disease on apple fruit. Plant Dis. 81: 1123-1126.

Crisosto, C., Mitchell, F., and Johnson, S. 1995. Factors in fresh market stone fruit quality. Postharvest News Inf. 6:17-21.

Crisosto, C. H., Johnson, R. S., Day, K. R., Beede, B., and Andris, H. 1999. Contaminants and injury induce inking on peaches and nectarines. Calif. Agric. 53:19-23.

Hu, M.-J., Peng, C., Melgar, J. C., and Schnabel, G. 2017. Investigation of potential causes of peach skin streaking. Plant Dis. 101:1601-1605.

Layne, D. R. 2007. Numerous factors affect peach quality. American Fruit Grower 42.

MacLean, D. C., Weinstein, L. H., McCune, D. C., and Schneider, R. E. 1984 Fluoride-induced suture red spot in 'Elberta' peach. Environ. Exp. Bot. 24: 353-367.

Proctor, J. T. A. 1983. Effect of simulated sulfuric acid rain on apple tree foliage, nutrient content, yield and fruit quality. Environ. Exp. Bot. 23:167-169, 171174.

Rinallo, C., and Modi, G. 1995. Fruit yield of field-grown pear Pyrus communis (L) exposed to different levels of rain acidity in Tuscany. J. Sci. Food Agric. 68:43-50.

Sawada, H., and Kohno, Y. 2009. Differential ozone sensitivity of rice cultivars as indicated by visible injury and grain yield. Plant Biol. 11:70-75.

Torskangerpoll, K., and Andersen, Ø. M. 2005. Colour stability of anthocyanins in aqueous solutions at various $\mathrm{pH}$ values. Food Chem. 89: 427-440.

USDA Agricultural Marketing Service. 2004. United States Standards for Grades of Peaches. USDA-AMS

Wohlgemuth, H., Mittelstrass, K., Kschieschan, S., Bender, J., Weigel, H.-J., Overmyer, K., and Langebartels, C. 2002. Activation of an oxidative burst is a general feature of sensitive plants exposed to the air pollutant ozone. Plant Cell Environ. 25:717-726. 